\title{
Spontaneous pneumomediastinum: A rare benign entity
}

\author{
Michalis Gerazounis, MD \\ Kalliopi Athanassiadi, MD \\ Nikolitsa Kalantzi, MD \\ Marios Moustardas, MD
}

\footnotetext{
From the Department of Thoracic Surgery, General Hospital of Nikea, Piraeus, Greece.

Received for publication July 1, 2002; revisions requested Aug 19, 2002; revisions received Sept 11, 2002; accepted for publication Oct 10, 2002

Address for reprints: Kalliopi Athanassiadi, MD, 34A Konstantinoupoleostr., 15562 Holargos, Athens, Greece (E-mail: kallatha@otenet.gr).

J Thorac Cardiovasc Surg 2003;126:774-6

Copyright $\odot 2003$ by The American Association for Thoracic Surgery

$0022-5223 / 2003 \$ 30.00+0$

doi:10.1016/S0022-5223(03)00124-7
}

Objective: Spontaneous pneumomediastinum usually occurs in young people without an apparent precipitating factor or disease. Thoracic surgeons are involved in the diagnosis and management of this entity because of the potentially life-threatening conditions that either must be treated as an emergency or excluded, such as esophageal perforation or necrotizing mediastinitis. We present our modest experience in treating spontaneous pneumomediastinum.

Materials: Between 1988 and 1998 we treated 22 cases of spontaneous pneumomediastinum in 18 male patients and 4 female patients, ranging in age between 12 and 32 years. All traumatic cases were excluded. Retrosternal chest pain was the main symptom the patients presented. In only 11 cases was subcutaneous emphysema present. Chest radiography was diagnostic in all our cases. Computed tomographic scan, when performed, confirmed the diagnosis. An esophagogram was essential to exclude an esophageal rupture. Last, a cardiologic examination especially focusing on pericarditis excluded cardiac disease.

Results: Conservative treatment consisted of bed rest, oxygen therapy, and analgesics, which led to rapid resolution of the spontaneous pneumomediastinum. The mean hospital stay ranged between 3 and 10 days. In a follow-up of 3 to 12 years only 1 recurrence was observed.

Conclusion: Spontaneous pneumomediastinum is usually an undiagnosed benign entity that responds very well to conservative treatment. It should be considered in the differential diagnosis of chest pain, especially in healthy adolescents and young adults.

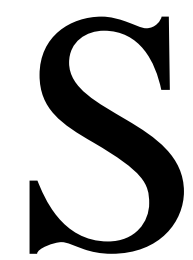

pontaneous pneumomediastinum (SPM) is a rare, self-limited disorder that usually occurs in young adult men without an apparent precipitating factor or disease. ${ }^{1-3}$ Thoracic surgeons are involved in the diagnosis and management of this entity because of the potentially life-threatening conditions that either must be treated as an emergency or excluded. We present our modest experience in treating SPM.

\section{Patients}

Between 1988 and 1998 we treated 22 cases of SPM in 18 male patients and 4 female patients, ranging in age between 12 and 32 years. All traumatic cases were excluded. Retrosternal chest pain was the main symptom the patients presented (Table 1). In only 11 cases was subcutaneous emphysema present (Table 2). Five of these patients also had rhinolalia due to the presence of cervical emphysema because of retropharyngeal dissection. Thirteen patients had dyspnea, although their blood gas analysis was normal $\left(72 \mathrm{~mm} \mathrm{Hg}<\mathrm{PCO}_{2}<85 \mathrm{~mm} \mathrm{Hg}, 34 \mathrm{~mm} \mathrm{Hg}<\mathrm{PCO}_{2}<\right.$ $41 \mathrm{~mm} \mathrm{Hg}$ ) and 6 had cough a few days before the acute onset.

None of our patients had pulmonary disease and 10 of them were smokers. Physical examination revealed (besides subcutaneous emphysema) the so-called "Hamman's sign" in 9 cases. 
TABLE 1. Symptoms present in our patients

\begin{tabular}{lr}
\hline Symptoms & $\mathbf{n}$ \\
\hline Retrosternal pain & 16 \\
Rhinolalia & 5 \\
Cervical edema & 5 \\
Dyspnea & 13 \\
Cough & 6 \\
\hline
\end{tabular}

TABLE 2. Clinical signs revealed by physical examination

\begin{tabular}{lr}
\hline Clinical signs & $\mathbf{n}$ \\
\hline Hamman's sign & 9 \\
Subcutaneous emphysema & 11
\end{tabular}

Chest and cervical radiography were diagnostic in all our cases (Figure 1). Computed tomographic (CT) scan, when performed $(n=9)$, confirmed the diagnosis of SPM and revealed in 1 case a concomitant pneumopericardium (Figure 2). Underlying disease was found only in 1 patient, a 27-year-old male smoker, in whom the CT scan demonstrated multiple small bullae at the apex of both lungs. He was the only patient who had a recurrence 1 year later. In all our cases the initial investigation included an esophagogram with meglumine diatrizoate (Gastrographin) to exclude any esophageal perforation. Last, a cardiologic examination focusing on pericarditis excluded cardiac disease.

\section{Results}

Conservative treatment consisted of bed rest, oxygen therapy, and analgesics. Oxygen therapy helped with the absorbance of mediastinal air and led to rapid resolution of the SPM. The mean hospital stay ranged between 3 and 10 days. In a follow-up of 3 to 12 years, only 1 recurrence was observed.

\section{Discussion}

SPM is a rare condition with an incidence of 1 per 7000 to 12,000 hospital admissions. ${ }^{2,4}$ The incidence we found in our series was 2 cases per 1000 hospital admissions and 1 case per 3578 patients examined in our department in the same period. It also represented the $0.08 \%$ of all cases of pneumomediastinum treated in our hospital. The male:female ratio was 8:1in our small series, similar to that of spontaneous pneumothorax $(6: 1)$.

Hamman $^{1}$ first described SPM in 1939. His description of audible crepitation occurring with the heartbeat on chest auscultation is known as "Hamman's sign," which was present in 9 of our cases.

According to Macklin and Macklin, ${ }^{5}$ pneumomediastinum results from the rupture of terminal alveoli into the lung interstitium and the dissection of air along the pulmo-

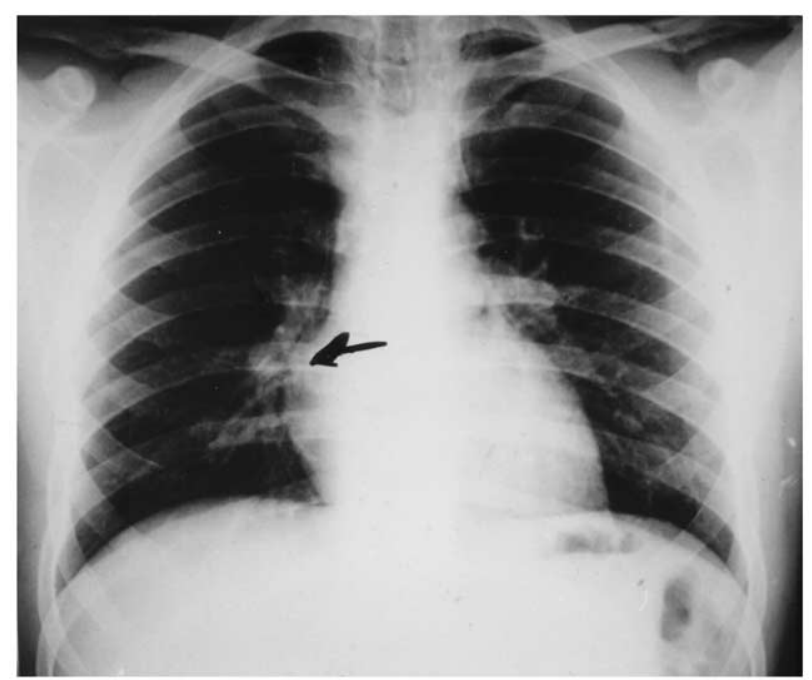

Figure 1. Chest radiograph showing mediastinal air with dissection to the neck (arrows).

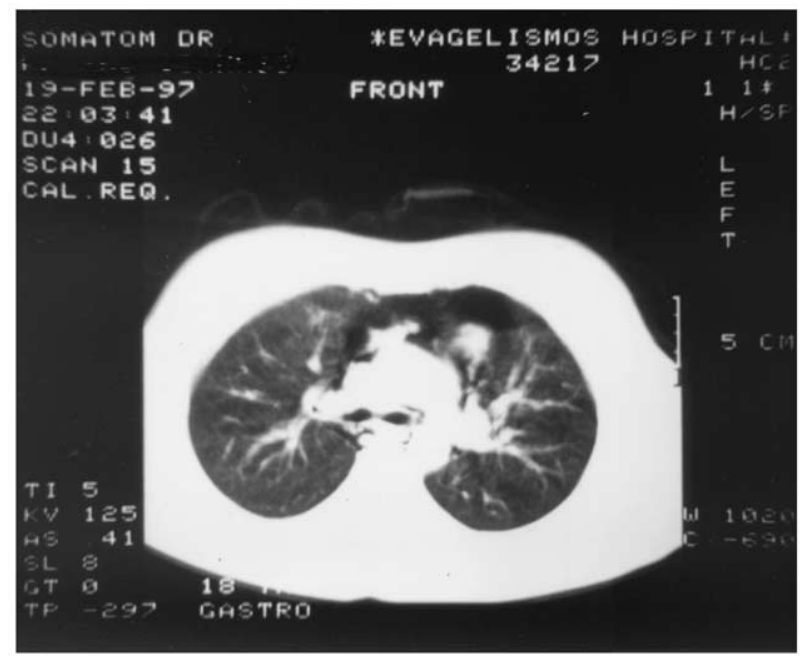

Figure 2. Computed tomogram showing spontaneous pneumomediastinum and pneumopericardium.

nary vasculature toward the hilum, with eventual extravasation into the mediastinum. This theory could explain only the 2 cases in which our patients reported having a cough. In the international literature SPM is reported to be the result of asthma, inhalation of drugs, ${ }^{6,7}$ labor, ${ }^{6}$ diabetic ketoacidosis, ${ }^{8}$ Hodgkin disease after irradiation, ${ }^{9}$ chemotherapy, ${ }^{10}$ coughing, or forceful straining during exercise $^{11,12}$ and other activities associated with the Valsava maneuver. ${ }^{6}$ With the exception of 1 patient with lung bullae formation, no underlying disease was found in our cases.

The presentation of SPM consists of acute onset of chest pain, ${ }^{2,3,13,14}$ as it was in our series, too. Symptoms such as dyspnea, dysphagia, and odynophagia have been also re- 
ported in the literature. ${ }^{13,15}$ Rhinolalia, ${ }^{16,17}$ developing as a consequence of cervical subcutaneous emphysema, is usually underestimated although present in the majority of cases. The initial differential diagnosis is broad, including musculoskeletal, pleural, pulmonary, cardiac, and esophageal causes. ${ }^{15}$ The presence of SPM was confirmed roentgenographically in all our cases. Esophageal studies with contrast material are essential to demonstrate any esophageal disease. CT scan was performed only to exclude any underlying pulmonary disease, as occurred in 1 of our patients who had multiple small lung bullae. ${ }^{18}$

Once more serious lethal causes are ruled out and the diagnosis is established, no special treatment is required and the patient can be discharged within the next 24 hours. Careful observation, bed rest, oxygen therapy, and analgesics comprissed the treatment we offered to our patients. Recurrence and complications are unusual and resolution of the symptoms is the rule. ${ }^{15,19}$ Among our patients, only 1 recurrence was observed during our follow-up period of 3 to 12 years, which seems to be the longest in the literature. ${ }^{3,13}$ No restrictions need to be followed by the patients and avoidance of predisposing factors is unnecessary.

In conclusion we would like to stress the following:

1. SPM is an often missed, benign entity that responds very well to conservative treatment.

2. SPM should be considered in the differential diagnosis of chest pain, especially in healthy adolescents and young adults.

\section{References}

1. Hamman L. Spontaneous mediastinal emphysema. Bull Johns Hopkins Hosp. 1939;64:1-21.

2. Munsel WP. Pneumomediastinum. JAMA. 1967;202:129-33.

3. Yellin A, Gapany-Gapanaticus M, Liebermann Y. Spontaneous pneu- momediastinum: is it a rare cause of chest pain? Thorax. 1983;38: 383-5.

4. McMahon DJ. Spontaneous pneumomediastinum. Am J Surg. 1976; 131:550-1

5. Macklin MT, Macklin CC. Malignant interstitial emphysema of the lungs and mediastinum as an important occult complication in many respiratory diseases and other conditions: an interpretation of the clinical literature in the light of laboratory experiment. Medicine. 1944;23:281-358.

6. Panacek EA, Singer AJ, Sherman BW, Prescott A, Rutherford WF. Spontaneous pneumomediastinum: clinical and natural history. Ann Emerg Med. 1992;21:67-72.

7. Beauchamps G. Spontaneous pneumothorax and pneumomediastinum. In: Pearson FG, Deslauriers J, Ginsberg RJ, Hiebert CA, McKneally MF, Urschel HC, editors. Thoracic surgery. New York: Churchill Livingstone; 1995. p. 1037-54.

8. Weathers LS, brooks WG, DeClue TJ. Spontaneous pneumomediastinum in a patient with ketoacidosis: a potentially hidden complication. South Med J. 1995;88:483-5.

9. Kim KI, Lee JW, Lee CH, Park SK. Polypoid endobronchial Hodgkin's disease with pneumomediastinum. Br J Radiol. 1999;72: 392-4.

10. Sikdar T, Macvivar D, Husband JE. Pneumomediastinum complicating bleomycin related lung damage. Br J Radiol. 1998;71:1202-4.

11. Partridge RA, Coley A, Bowie R, Woolard RH. Sports-related pneumothorax. Ann Emerg Med. 1997;30:539-41.

12. Morgan EJ, Henderson DA. Pneumomediastinum as a complication of athletic competition. Thorax. 1981;36:155-6.

13. Abolnik I, Lossos IS, Breuer R. Spontaneous mediastinum; a report of 25 cases. Chest. 1991;100:93-5.

14. Bodart E, de Bilderling G, Nisolle JF, Trigaux JP, Tuerlinckx D. Pneumomediastin spontané chez un adolescent: une cause sous-estimée des douleurs thoraciques. Arch Pediatr. 1999;6:1293-6.

15. Ralph-Edwards AC, Pearson FG. Atypical presentation of spontaneous pneumomediastinum. Ann Thorac Surg. 1994;58:1758-60.

16. Hoover LR, Febinger DL, Tripp HF. Rhinolalia: an underappreciated sign of pneumomediastinum. Ann Thorac Surg. 2000;69:615-6.

17. Sleeman D, Turner R. Spontaneous pneumomediastinum with alteration in voice. J Laryngol Otol. 1989;103:1222-3.

18. Dosios T, Fytas A, Zarifis G. Spontaneous epidural emphysema and pneumomediastinum. Eur J Cardiothorac Surg. 2000;18:123.

19. Channer KS. Recurrent idiopathic pneumomediastinum. Postgrad Med J. 1985;61:1073-5. 